\title{
Sobre jornalismo e homofobia ou: pensa que é fácil falar?
}

\section{Bruno Souza Leal e Carlos Alberto de Carvalho}

\section{Resumo}

Este artigo tem como objetivo apresentar discussões iniciais que forneçam condições para que as relações entre jornalismo e homofobia sejam melhor apreendidas, tomando como objeto alguns veículos da "mídia de referência" brasileira. Para tal, parte de uma compreensão da organização da vida sexual, com foco naquilo que contribui para as ações e discursos homofóbicos e/ ou sobre a homofobia, para em seguida observar o processo jornalístico de construção das realidades. Articulando uma e outra, estão os desafios nos modos de dizer do jornalismo, premido pelos silêncios, ambigüidades e usos lingüísticos tradicionais e contemporâneos que a moral sexual, as questões de gênero e a homofobia e seu combate impõem. Não se propõe, portanto, aqui, a análise específica de algum caso de homofobia que tenha tido cobertura jornalística, mas apenas se indicam alguns elementos que se apresentam como importantes para um estudo que tenha tal temática como objeto de investigação.

Palavras-chave

Jornalismo. Gênero. Homofobia.

\section{Bruno Souza Leal | brunosleal@gmail.com}

Doutor em Estudos Literários pela Universidade Federal de Minas Gerais - UFMG. Pesquisador permanente do Programa de PósGraduação da UFMG.

\section{Carlos Alberto de Carvalho | caco5@uol.com.br}

Doutorando em Comunicação Social pela Universidade Federal de Minas Gerais - UFMG. Professor do Curso de Comunicação Social/ Jornalismo da Universidade Federal de Ouro Preto - UFOP.

\section{Introdução}

Segundo dados de pesquisa feita na Parada Gay de São Paulo em 2005 (CARRARA; RAMOS; SIMÕES; FACCHINI, 2006,), 72,1\% das mais de dois milhões de pessoas ali presentes informaram que já haviam sofrido alguma forma de discriminação em função de sua identidade, orientação e/ou prática sexual. Na mesma pesquisa, $67,5 \%$ disseram que já tinham sofrido agressões físicas pelas mesmas razões. Uma outra pesquisa, realizada em 2006 sob coordenação do professor do Departamento de Psicologia da Universidade Federal de Minas Gerais, Marco Aurélio Máximo Prado, com os freqüentadores da Parada Gay de Belo Horizonte, por sua vez, revelou que $43 \%$ dos ali presentes "confiavam pouco" na imprensa. No entanto, essa era das instituições de maior credibilidade entre as analisadas. Cerca de 19\% das pessoas indicaram que confiavam muito na imprensa, índice significativamente maior que os da Polícia (4,6\%), da Justiça (8,9\%) e do Congresso Nacional (6,6\%).

Esses dados apresentam variações de gênero, orientação sexual, idade, entre outros, mas 
certamente são indicadores, por um lado, do quão disseminada a homofobia se encontra na sociedade brasileira, e, por outro, de uma certa ambiguidade na percepção do papel da imprensa. Afinal, como explicar que o jornalismo seja uma instituição das mais credíveis, mesmo sendo pouco confiável? Uma vez que o jornalismo vive de notícias, uma primeira hipótese é que sua credibilidade viria da boa cobertura de casos de homofobia, assim como da agenda política e do universo cultural de Lésbicas, Gays, Bissexuais, Travestis, Transexuais e Transgêneros (LGBT). Nesse caminho, o jornalismo seria um espaço importante de visibilidade, tanto para denúncias de violência, quanto para reivindicações de direitos e, ainda, para a chamada "cultura GLS". Numa outra direção, a segunda hipótese sugere que a pouca confiabilidade adviria dos silêncios e das omissões - ou seja, do não reconhecimento da noticiabilidade de fatos relacionados à homofobia e a indivíduos e entidades LGBT - e de discordâncias frente ao modo como notícias deste ou daquele veículo são construídas.

Tendo em vista apenas a grande imprensa brasileira, a chamada "mídia de referência", 0 conjunto de variáveis que regem o entendimento de noticiabilidade ou o tratamento de situações homofóbicas, por exemplo, vai desde a identidade do veículo, sua relação com o público-leitor e seu posicionamento político-ideológico, passando por aspectos "técnicos" e/ou circunstanciais, como a estrutura organizacional e a disponibilidade de espaço ou tempo, e chegando a atingir mesmo a leitura individual que cada jornalista, inserido na cadeia produtiva da notícia, faz dos eventos capturados pela rede noticiosa. Se uma explicação não é fácil nem simples, não é possível negar, porém, que a disseminada homofobia brasileira traz desafios aos modos de dizer do jornalismo. Em que pese mesmo a existência de veículos segmentados, pró e contra os direitos LGBT, a grande imprensa, como parte da sociedade brasileira, não é imune às tensões que marcam as construções de gênero e sexualidade no país, e às quais a própria noção de homofobia - e os fenômenos por ela nomeados - está intrinsecamente ligada.

Essas tensões se inscrevem nas disputas de sentido que diversos atores sociais buscam imprimir à informação jornalística sobre as questões do universo da sexualidade. Dentre estes atores, é importante lembrar as religiões, especialmente a Católica, as instâncias de defesa dos direitos humanos e da comunidade LGBT, os partidos políticos e uma grande quantidade de instituições ligadas aos diversos níveis do exercício do poder estatal e governamental, além de organizações não governamentais de âmbito local, nacional e internacional. Essa disputa político-ideológica tem nos próprios jornais alguns de seus atores mais importantes. Afinal, cada jornal não só define o que deve ou não ser notícia, estabelecendo uma hierarquia dos acontecimentos, como organiza e dispõe nexos entre fatos e os seus agentes e pacientes, legitimando saberes e discursos. Assim, a 
complexidade das relações entre jornalismo e homofobia diz tanto da normatividade da vida sexual na sociedade brasileira, quanto das disputas aí presentes e, além disso, da própria ação dos jornais, em sua especificidade.

Nesse quadro, este $\operatorname{artig}^{1}$ tem como objetivo apresentar discussões iniciais que forneçam condições para que as relações entre jornalismo e homofobia sejam melhor apreendidas. Para tal, parte de uma compreensão da organização da vida sexual, com foco naquilo que contribui para as ações e discursos homofóbicos e/ou sobre a homofobia, para em seguida observar 0 processo jornalístico de construção das realidades. Articulando uma e outra, estão os desafios nos modos de dizer do jornalismo, premido pelos silêncios, ambiguidades e usos linguísticos tradicionais e contemporâneos que a moral sexual, a homofobia e seu combate impõem. Não se propõe, portanto, aqui, a análise específica de algum caso de homofobia que tenha tido cobertura jornalística, mas apenas a indicação de alguns elementos que se apresentam como importantes para um estudo que tenha tal temática como objeto de investigação.

\section{0 s desafios de um conceito e a complexidade de um fenômeno}

Termo relativamente novo no vocabulário brasileiro, "homofobia" surge conceitualmente vinculado aos estudos de gênero e sexualidade, que vêm apontando, já faz algum tempo, a dissociação entre prática sexual, identidade sexual e de gênero (FOUCAULT, 2006; ARIÉS \& BÉJIN, 1985; PARKER; BARBOSA, 1996; COSTA, 2002, e outros), as ambiguidades desses scripts (GAGNON, 2006, PARKER, 2002), a pluralidade de modelos identitários e de formas de vínculo afetivo e sexual (MATOS, 2000) e a historicidade das identidades sexuais e de gênero (FRY, 1982; PARKER, 2002; GREEN, 2000; COSTA, 2002, entre vários outros). Com um uso cada vez mais corrente, o termo tem ao mesmo tempo grande amplitude e limitações óbvias. Começando pelas últimas, é fácil observar sua ambigüidade. Afinal, a partícula "homo" tem dois usos, sendo um deles mais tradicional, que remete ao "igual" e a partir do qual o termo significaria "medo do semelhante". 0 outro uso, mais contemporâneo, traz a associação com a homossexualidade, como em "homoparentalidade", por exemplo, e, dessa forma, "homofobia" designaria então ódio ou repulsa aos homossexuais. Por outro lado, a expressão "fobia" dá um peculiar acento psicológico a essa repulsa, ressaltando, talvez em demasia, aspectos individuais de um fenômeno social.

Por mais que o termo tenha certamente problemas, é importante notar que sua ambigüidade não é gratuita e diz um pouco da complexidade dos fenômenos que nomeia. 
Afinal, "homofobia" se filia à série de termos que marcam formas de discriminação, como racismo, sexismo, antissemitismo ou xenofobia. Em todos os casos, retira-se ou reduz-se a humanidade de um grupo de pessoas, recusando-se sua igualdade frente aos demais. Assim, como observa Karin Smigay (2002), a compreensão da homofobia ultrapassa os estudos isolados de preconceito social e de cunho psicanalítico, exigindo atenção às relações de poder, de gênero e de sexualidade presentes na cultura e que definem a própria constituição dos indivíduos. Dessa forma, a homofobia, como o sexismo e a violência de gênero, se manifesta tanto na esfera do indivíduo - na relação consigo e com o outro - quanto nas matrizes culturais de uma sociedade.

Daniel Borrillo (2001), nesse sentido, faz a distinção entre uma homofobia "psicológica", individual, e outra "cognitiva", social, por considerar que ela pode se apresentar tanto como uma manifestação emocional tipicamente fóbica, envolvendo, por exemplo, náuseas, asco, mal estar, quanto como "[...] basear um conhecimento do homossexual e da homossexualidade sobre um preconceito que os reduz a um clichê" (p.26). Uma das faces mais visíveis da "homofobia cognitiva", segundo Borrillo, está presente nas piadas, nos insultos e nas formas de representação caricaturais, habituais na linguagem coloquial, e que reduzem pessoas gays, lésbicas, bissexuais e transgênero a grotescos personagens de escárnio. É importante deixar claro que para 0 autor o "mal estar" do indivíduo é tributário das construções sociais dos gêneros e das sexualidades, não podendo ser associado, portanto, a causas biológicas.

Pode-se perceber, então, que a homofobia tem um componente intragênero (entre as diversas formas de ser homem ou mulher) e outro entre gêneros ( 0 outro - seja outro gênero, seja 0 transgênero). Com isso, a homofobia pode ser vista como vinculada aos "problemas de gênero", (BUTLER, 2003), ou seja, às formas sociais de construção das identidades de gênero, e à repulsa ao reconhecimento do gênero - e das práticas e identidades sexuais - como uma construção cultural. Assim sendo, a homofobia não pode ser definida simplesmente como antipatia, ódio, condenação, medo ou proscrição aos homossexuais, tal como faz Fone (2000). 0 próprio autor observa que a "homofobia" não é exclusiva de heterossexuais, podendo ser encontrada entre sujeitos homoeroticamente inclinados do mesmo modo que o racismo, 0 sexismo ou outra forma de discriminação. Isso implica reconhecer a homofobia como vinculada às matrizes normativas de construção de gênero e das identidades sexuais, ampliando seu alcance a todos os indivíduos que se posicionam ou se consideram distantes (em maior ou menor grau) da norma sexual.

A homossexualidade e os homossexuais seriam 0 alvo mais visível de atitudes e ações homofóbicas exatamente porque constituem o outro a partir do qual a normalidade se afirma. Borrillo (2001) 
observa que a homofobia tem no heterosexismo uma de suas faces, sendo um dos componentes fundamentais na elaboração da identidade masculina, o lugar de poder nas sociedades andro e falocêntricas. A partir do pensamento de E. Badinter, Borrillo afirma que, uma vez que um homem é um "artefato","[a] homofobia e, em particular a homofobia masculina, desempenha uma função de 'polícia da sexualidade', reprimindo qualquer comportamento, qualquer gesto ou qualquer desejo que transborde as fronteiras 'impermeáveis' do gênero" (2001, p.95). A partir dessa percepção, é possível reconhecer, sinteticamente, pelo menos três elementos da norma sexual que fundam a homofobia:

a) a percepção de que a reprodução constitui 0 fim, natural e biológico, das relações sexuais; b) a naturalização da distinção homem/mulher, ou seja, da crença histórica da existência biológica de dois corpos e dois gêneros e mais ainda o estabelecimento dessa distinção como fundamento último, como "essência" das identidades de gênero ${ }^{2}$;

c) a organização produtiva dos corpos e demais dispositivos de gênero, como a sexualidade, a partir dessa dicotomia.

Em outras palavras, a norma sexual ocidental define que há, na natureza do ser humano, dois sexos, ao mesmo tempo origem e destino dos indivíduos. Sendo assim, organiza toda a lógica de gênero e os modos de construção dos corpos, orientados para a expressão dessa diferença fundamental. Com isso, toda sexualidade e todo ato sexual justificam-se no encontro desses dois corpos e na reprodução da espécie. Qualquer prática sexual não reprodutiva é certamente um desvio, da mesma forma que qualquer elaboração dos corpos que desnaturalize ou torne ambíguas as construções de gênero e ponha em questão, por fim, a pretensa naturalidade da dicotomia homem/mulher.

Considerando, como já havia alertado Foucault (2006), que a sexualidade é alvo de discursos de verdade, encontra-se na vida social todo um conjunto de atores sociais que, partindo de princípios e/ou fins morais, educativos, políticos, médicos ou religiosos, tem no combate à homossexualidade e aos direitos LGBT uma estratégia fundamental de reafirmação da norma de gênero e sexual. Esses discursos circulam na vida social reforçando e mesmo legitimando saberes e comportamentos homofóbicos, para os quais inclusive a conquista de direitos surge como disruptora da família e das instituições sociais.

É assim que, ao longo da história, lembra Borrillo (2001), tais percepções não têm resultado apenas em atos de homofobia circunscritos às relações 
sociais cotidianas, mas levaram, em diversos momentos, a ações legais, em diversos tempos e locais, de criminalização de certa(s) prática(s) sexual(ais), ainda que recebendo nomenclaturas distintas, por parte de regimes monárquicos, monárquicorreligiosos e mesmo "republicanos". No plano religioso, a Igreja Católica não somente estimulou, como também adotou a prática da fogueira para as "sexualidades desviantes", processo semelhante àquele promovido contra atos de bruxaria, cientistas revolucionários e quem mais fosse considerado (a) fora dos padrões de normalidade para a instituição religiosa. Mais recentemente, a mais trágica memória dos resultados da homofobia é 0 "holocausto" promovido pelo Nazismo, com o extermínio em massa de homossexuais nos campos de concentração, identificados por um triângulo rosa em suas vestimentas. Homossexuais, judeus, comunistas e outros "párias", aos olhos do nazismo, representaram ameaças ao ideal de raça pura punidos com a eliminação física. Por seu turno, a ciência - especialmente a médica, a psicológica e a psicanalítica - tem desempenhado papéis, ora de ambiguidade, ora de clara hostilidade a qualquer sexualidade não heterossexista e reprodutiva, tal como atentam, entre outros autores, Borrillo (2001) e Foucault (2006).

Nesse sentido, é importante observar, como faz Borrillo (2001), que a distinção formal entre homofobia psicológica e cognitiva marca a amplitude dos comportamentos e formas simbólicas que materializam esse rechaço ao que representa a quebra da normalidade. Borrillo comenta que mesmo quando uma pessoa tem amigos homossexuais, por exemplo, sentido-se então confortável em sua companhia, isso não implica o reconhecimento dos seus direitos civis e da legitimação de um estilo de vida. Assim, a homofobia, componente da norma sexual e presente na série de processos que naturalizam gêneros e sexualidades, manifestase tanto nos xingamentos e comentários jocosos quanto na violência física, bem como sob formas aparentemente mais brandas de "tolerância", de recusa à visibilidade de problemas sociais, na individualização de comportamentos e atitudes discriminatórios.

Verifica-se então que são amplas as formas do dizer que, fundamentais à materialização da norma sexual, definem também os espaços de tensão, os saberes e comportamentos homofóbicos e aqueles que os combatem. Afinal, o silêncio e a omissão, pautados pela interdição ou pela indiferença, são tão desumanizadores quanto os xingamentos e a ofensa. Assim como a homofobia manifesta-se explicitamente em discursos, apresenta-se também nas alusões, nas lacunas e na recusa à nomeação e aos usos de termos que deixem clara a diversidade sexual. A resistência e 0 combate à homofobia, por sua vez, podem surgir tanto em discursos que claramente marcam seus posicionamentos como através de estratégias irônicas e parodísticas de ressemantização de expressões homofóbicas. 
Em todos os casos, estão em questão as formas de visibilidade, de indivíduos e comportamentos, da agenda de direitos humanos, das diversas manifestações culturais LGBT, e também do que é apresentado como comum e normal.

\section{A notícia entre 0 dito e o não-dito}

Os veículos jornalísticos, mais que reprodutores da vida social, constituem-se como instâncias de construção da realidade, que dialogam, com maior ou menor poder, com outras instituições, como o Estado, a família e a Universidade. Como observa França (1998), a palavra do jornal é uma palavra social, pois está calcada na apreensão dos discursos existentes num dado contexto historicossocial. Os mundos das páginas de jornais ou vistos na tevê não são, portanto, necessariamente os mesmos e revelam, como obras de linguagem, que têm freqüentemente uma feição narrativa, ordenadora de tempos, espaços, identidades e relações, sendo periodicamente ofertados à população (TRAQUINA, 1993). Quanto maior a familiaridade e 0 contato com esses veículos, mais o leitor/ espectador terá esse (s) mundo (s) como a realidade, parâmetro para suas relações no cotidiano (GUMBRECHT, 1998).

Postas em circulação, as notícias repercutirão no sentido de agendar temas para debates, informando ao público sobre questões que estão na "ordem do dia". Da mesma forma, o próprio público agenda a mídia noticiosa, a partir de demandas para que ela dê visibilidade a temas que lhe interessa, e as mídias agendam-se mutuamente, a partir da repercussão de temáticas de amplo apelo social. (PONTE, 2005; TRAQUINA, 1993; e WOLF, 1994). Nesse sentido, é importante observar que parte da estratégia do movimento social LGBT vai na direção de produzir eventos que pautem os veículos jornalísticos, "exigindo" sua cobertura, como é o caso das Paradas de Orgulho LGBT e as manifestações do Dia Nacional de Combate à Homofobia e do Dia Internacional de Combate à Aids.

Lugares de identidade e identificação (SODRÉ, 1996; VERÓN, 2001 entre outros), as mídias noticiosas não podem assim ser vistas como espaços neutros ou meramente técnicos. As notícias, por exemplo, se configuram como um produto - o que implica em processo, racionalidade e técnica - intimamente associado a estratégias que supõem enquadramentos e critérios de noticiabilidade - variáveis que os jornalistas e veículos utilizam para decidir o que merece ou não aparecer na mídia como notícia, a partir de um cardápio de acontecimentos. (GOMIS, 1991; MOUILLAUD, 1997; PONTE, 2005; TRAQUINA, 1993; e WOLF, 1994)

Esse saber o mundo que as narrativas jornalísticas põem em circulação, portanto, é decisivo para o modo como os diversos grupos sociais constroem sua realidade e elaboram sua percepção do cotidiano. Uma vez que a racionalidade jornalística é indissociável da cultura organizacional das empresas e do 
processo de produção da notícia (TUCHMAN, 1977; MOURA, 2006), e aberta às pressões e tensões da vida social, considera-se que esse saber não seria o mesmo nem de veículo a veículo, nem em cada cobertura. Essa forma de tomar conhecimento dos acontecimentos sociais, portanto, é o que nos diz sobre uma maneira muito particular que as mídias noticiosas têm de organização da "realidade" que elas nos apresentam.

Segundo Adelmo Genro Filho (1987), o jornalismo apresenta a(s) realidade(s) necessariamente a partir de "fragmentos", pois tem na singularidade dos acontecimentos 0 seu modo de organização do mundo. Ele difere, portanto, de discursos como o filosófico e o científico, que teriam na universalidade 0 objetivo de suas explicações. A singularidade se materializaria na opção dos jornais por nomes, datas e circunstâncias específicas. Ou seja, não se apresenta um caso genérico, mas a notícia do que aconteceu com fulano de tal, no dia tal, cidade tal, de tal forma. Porém, Genro alerta que, a cada acontecimento anunciado em sua singularidade tem-se, mais do que a fragmentação, a indicação dos aspectos mais gerais, chamados por ele de "particulares". Assim, no exemplo de um assassinato de uma pessoa homossexual, a particularidade está nas condições mais gerais que 0 orienta, para além dos seus aspectos singulares. No entanto, para 0 autor, se a singularidade é reveladora de particularidades, ela tende à revelação da universalidade, que, nesse caso, está na existência de práticas e discursos homofóbicos na sociedade que é palco daquele assassinato.

A proposição de Genro Filho, portanto, se inscreve na linha dos que defendem a radicalidade da marca social nas produções jornalísticas. Nas palavras do autor:

Por isso, a informação jornalística não é contrária à formação da experiência: trata-se, inclusive, de uma experiência que já vem, em alguma medida, 'pré-formada' pelos mediadores e pelo sistema jornalístico no qual estão inseridos; noutro sentido, essa experiência 'pré-formada' não resulta pronta e acabada, mas convida 0 público a completá-la como um fenômeno que estivesse sendo percebido diretamente. A sua significação universal, está apenas sugerida ao invés de formalmente fixada. A concepção ingênua de que 0 jornalismo inevitavelmente fragmenta 0 real e, em conseqüência, é necessariamente manipulatório e alienante, sequer consegue notar que a singularidade é uma dimensão objetiva da realidade e, além disso, que 0 singular também contém o particular e 0 universal. (GENRO FILHO, 1987, p. 209, grifo do autor)

Partindo dessas premissas, percebe-se que as narrativas jornalísticas sobre a homofobia, mais do que a revelação de casos singulares, estão indicando modos de organização das sexualidades. Tais acontecimentos, quando apreendidos pela produção noticiosa, passam a conter uma carga social que não se esgota na singularidade do fato relatado. Potencialmente, a leitura está apontando na direção de reconhecimento, pelo leitor, de fatos que projetam um desenho de sociedade. Do mesmo modo, os silêncios sobre a homofobia, 
suas práticas e suas conseqüências compõem 0 universo dos "discursos" das mídias, à medida que não falar sobre um determinado tema não é simplesmente desconhecê-lo, mas resulta de uma escolha consciente, marcada, no mínimo, por "critérios de noticiabilidade", nunca neutros, apesar de dotados de uma suposta racionalidade.

Por outro lado, em certa medida parece haver concordância entre o que pensam Genro Filho e analistas do discurso como Patrick Charaudeau (2006), para quem a informação jornalística parte de um mundo "pré-significante" para torná-lo "significante". Porém, enquanto Genro Filho acentua o modo peculiar de o jornalismo saber - e dar sentido - ao mundo, Charaudeau (2006) destaca a dimensão relacional que marca os contratos mediáticos. Afinal, as notícias são destinadas a uma audiência e para ela orientadas. $\mathrm{Ou}$, como sintetiza Ponte (2005), "quem formula 0 discurso tem em conta parâmetros relacionais para com seu auditório: a sua identidade e seus conhecimentos, o efeito de influência que pretende, o tipo de relação e regulação em que operam" (2005, p. 109, grifos da autora).

Com isso, vem à cena uma dimensão fundamental na relação jornalismo/homofobia, que se apresenta como uma instância decisiva de mediação dos saberes e discursos sociais, pois os interpreta, hierarquiza e organiza: o próprio veículo jornalístico, na sua especificidade como ator social. Afinal, cada jornal tem sua "identidade" (LANDOWSKI, 1992; FRANÇA, 1998) capaz de ser reconhecida pelos leitores, numa relação que inclusive contribui para as estratégias de sentido das notícias e sua apreensão no cotidiano. Lembra MOUILLAUD (1997), nesse sentido, a importância e as funções do nome do jornal, responsável pela sua identidade sob diversos ângulos: em relação aos demais veículos, para diferenciá-lo; na sucessão periódica das edições, como um "grampo" que os junta e dá sentido, para além de sua especificidade; ao estabelecer um "princípio de espera" e posse no leitor, que no tempo peculiar das edições, aguarda o reconhecimento do seu jornal, e assim por diante.

Para Mouillaud (1997), é importante ressaltar, tanto jornal como notícia são dispositivos, pois articulam materialidade física, tecnologia, processos organizacionais, narrativos e comunicacionais. Um dispositivo, alerta ele, não é um suporte, mas uma "matriz", que impõe suas formas e condições aos produtos. Na articulação jornal e notícia, Mouillaud (1997) ressalta que esta pode "aparecer" como sedimentação daquele e vice-versa. Ou seja, tomados como dispositivos, jornal e notícia se encaixam e determinam-se de maneira variada. Da mesma forma que o jornal precede seus textos, portanto conformando-os às suas condições econômicas, de público, de capacidade técnica etc., as notícias, na sua especificidade, pressionam os veículos cotidianamente, a ponto de aquelas "fora de norma" poderem, para 0 autor, deformar 0 dispositivo do jornal e até mesmo implodi-lo (MOUILLAUD, 1997,p.34). 
A percepção da diferença e da articulação entre jornal e notícia é fundamental para que se vejam as possíveis contradições existentes entre cada veículo, suas edições e suas notícias. Assim, por exemplo, o enquadramento (TUCHMAN, 1977) de cada notícia não necessariamente exclui contradições nem se mantém nas demais. Por enquadramento, entendem-se as visões que o jornalismo apresenta de um determinado tema, o que implica tanto uma concepção de mundo como estratégias narrativas, a exemplo dos textos construídos a partir de abordagens sensacionalistas. (TUCHMAN, 1977; TRAQUINA, 1993; SILVEIRINHA, 2005)

Os enquadramentos são, portanto, da ordem da relação que os jornais mantêm com a sociedade e, conseqüentemente, as notícias contêm, potencialmente pelo menos, múltiplas vozes, como as fontes ouvidas na sua preparação, a linha editorial de cada veículo e o jornalista responsável pela recolha de dados e redação. A cada notícia, a cada segmento narrativo, porém, esse jogo de vozes é reorganizado e hierarquias são estabelecidas, a partir mesmo dos interesses político-ideológicos e morais em questão. Dessa forma, é importante observar que o fato da palavra do jornal ser fundamentalmente social não faz com que automaticamente esta ou aquela matéria seja polifônica, no sentido dado ao termo por Bakhtin (1979). Afinal, todas as vozes mobilizadas numa notícia podem advir de um mesmo lugar social, ou seja, representarem uma mesma "voz".

Em outras palavras, é importante observar que a orquestração das vozes sociais no jornalismo é estabelecida numa cadeia de relações que vão desde a identidade do veículo, passando pela peculiaridade de cada edição e de cada notícia. Não há certamente nenhuma garantia que enquadramentos se mantenham, que blocos ou cadernos não se contradigam ou mesmo que uma notícia fortemente homofóbica não tenha a companhia, páginas ou minutos depois, de uma outra, favorável ao combate da discriminação. "Quebrar" a inteireza do produto jornalístico ${ }^{3}$, observando os matizes, tons e rupturas na superfície noticiosa revelase um cuidado fundamental na apreensão do tratamento jornalístico do conjunto de tensões que constituem a organização da vida sexual brasileira. Afinal, jornais e notícias, menos que meros reprodutores, são sujeitos, determinados por essas tensões, mas também capazes de relativa autonomia, de ação e voz.

Nesse sentido, apreender as relações mídia/ homofobia é empreender um esforço de observação de contradições e diferenças, para além de determinações fáceis e visões homogeneizadoras rápidas. À afirmação de que tal ou qual jornal é favorável ou não ao combate à discriminação, cabe a leitura atenta 
de seus textos e às variações aí presentes.

Afinal, se essa leitura tem na linguagem e na narrativa seus pontos de apoio e inflexão, não se pode desconhecer os processos tecnológicos e organizacionais que os envolvem. Da mesma forma, importa verificar tanto o que é dito, quanto como é dito. Conseqüentemente, 0 não-dito, as lacunas e omissões têm igual importância, ao serem reveladoras de valorações e posicionamentos morais e ideológicos. Por fim, torna-se fundamental observar como os fatos noticiados são articulados, seja no interior da notícia, seja no nível maior de cadernos ou blocos e ainda na totalidade da edição do (tele/radio) jornal ou da revista.

Como visto acima, a homofobia é um fenômeno complexo o suficiente para trazer desafios à racionalidade e ao saber jornalístico, pois não se pode dissociar a emergência de atos homofóbicos das tensões identitárias, sexuais, morais, dos diversos grupos e realidades sociais específicas. A diversidade de identidades sexuais e de gênero - e das realidades culturais a elas ligadas - faz ver, portanto, que não só a homofobia se manifesta diferentemente, como sua emergência será percebida, "capturada", pelas redes noticiosas conforme um julgamento não só de sua relevância, mas também de sua representatividade. Sendo assim, o modo como as mídias narram a homofobia faz ver não só as tensões que as permeiam e aquelas da vida afetiva e sexual, mas também o(s) seu (s) modo (s) de saber o mundo e o leitor.

\section{Referências bibliográficas}

ARIÉS, P \& BÉJIN, A. (org.). Sexualidades

ocidentais. São Paulo: Brasiliense, 1985.

BAKHTIN, M. Marxismo e filosofia da linguagem.

São Paulo: Hucitec, 1979.

BHABHA, H. 0 local da cultura. Belo Horizonte:

UFMG, 2005.

BORRILLO, D. Homofobia. Barcelona: Belaterra, 2001.

BOURDIEU, Pierre. 0 poder simbólico. Rio de

Janeiro: Bretrand-Brasil, 1998.

BUTLER, Judith P. Problemas de gênero: feminismo e subversão da identidade. Rio de Janeiro: Civilização Brasileira, 2003.

CAMARGO JR. Kenneth Rochel de. As ciências da Aids e a Aids das ciências: 0 discurso médico e a construção da Aids. Rio de Janeiro: Abia/IMS/UERJ/ Relume Dumará, 1994.

CARRARA, Sérgio. Política, direitos, violência e homossexualidade. Rio de Janeiro: CEPESC, 2006. Pesquisa realizada na $9^{\mathrm{a}}$ Parada do Orgulho GLBT, São Paulo, 2005.

CARRARA, Sérgio; RAMOS, Silvia; SIMÕES, Julio Assis; FACCHINI, Regina. Política, direitos, violência e homossexualidade. Rio de Janeiro: Cepesc, 2006. Pesquisa realizada na $9^{\mathrm{a}}$ parada do orgulho GLBT São Paulo 2005.

CARVALHO, Carlos Alberto de. Visibilidades mediadas nas narrativas jornalísticas: a cobertura da Aids pela Folha de S. Paulo de 1983 a 1987. 2000. Dissertação (Mestrado em ÁREA)- Faculdade de Filosofia e Ciências Humanas, Universidade Federal de Minas Gerais, Belo Horizonte, 2000.

CHARAUDEAU, P. Discurso das mídias. São Paulo: Contexto, 2006

COSTA, Jurandir Freire. A inocência e o vício. 4. ed. Rio de Janeiro: Relume-Dumará, 2002. 
DUBY, Georges. Amor e sexualidade no ocidente. Lisboa: Terramar, 1991.

FONE, Byrne. Homophobia. Nova York: Picador, 2000.

FOUCAULT, M. História da Sexualidade 1 - a vontade de saber. 17. ed. Rio de Janeiro: Graal, 2006.

FRANÇA, Júnia Lessa et al. Manual para

normalização de publicações técnico-científicas.

7.ed. Belo Horizonte: UFMG, 2004.

FRANÇA, Vera Regina Veiga. Jornalismo e vida social: a história amena de um jornal mineiro. Belo Horizonte: UFMG, 1998.

FRY, Peter. Para inglês ver: identidade e política na cultura brasileira. Rio de Janeiro: Zahar, 1982.

GAGNON, John H. Uma interpretação do desejo: ensaios sobre 0 estudo das sexualidades. Rio de Janeiro: Garamond, 2006.

GENRO FILHO, Adelmo. 0 segredo da pirâmide: para uma teoria marxista do jornalismo. Porto Alegre: Tchê!, 1987.

GIDDENS, Anthony. As conseqüências da modernidade. São Paulo: Unesp, 1991.

GIDDENS, Anthony. Sociologia. Porto Alegre: Artmed, 2005.

GOMIS, Lorenzo. Teoría del periodismo - como se forma el presente. Barcelona: Paidós, 1991.

GREEN, James Naylor. Além do carnaval. São Paulo: Unesp, 2000.

GUMBRECHT, Hans. Modernização dos sentidos. Rio de Janeiro: 34, 1998.

HOHLFELDT, Antonio. Hipóteses contemporâneas de pesquisa em comunicação. In: HOHLFELDT, Antonio; MARTINO, Luiz C.; FRANÇA, Vera Veiga (orgs.). Teorias da comunicação: conceitos, escolas e tendências. Petrópolis: Vozes, 2001. p.187-240.
HOUAISS, Antônio; VILLAR, Muro de Salles.

Dicionário de língua portuguesa. Rio de Janeiro:

Objetiva, 2001.

LACQUER, Thomas. Inventando o sexo. Rio de Janeiro: Relume-Dumará, 2001.

LANDOWSKI, Eric. A sociedade refletida: ensaios de sociossemiótica. São Paulo: Educ/Pontes, 1992.

LEAL, Bruno Souza. Saber as narrativas: narrar. In: FRANÇA, Vera; GUIMARÃES, César. (orgs.).

Narrativas do cotidiano. Belo Horizonte: Autêntica, 2006. p. 19-28.

LOYOLA, Maria Andréa (org.). Aids e sexualidade - 0 ponto de vista das Ciências Humanas. Rio de Janeiro:

Relume-Dumará/UERJ, 1994.

MATOS, Marlise. Reinvenções do vinculo amoroso: cultura e identidade de gênero na modernidade tardia. Belo Horizonte: UFMG; Rio de Janeiro: IUPERJ, 2000.

MINISTÉRIO DA SAÚDE - Boletim Epidemiológico AIDS/ DST - Janeiro a Junho de 2006. Disponível em: <http://www.aids.gov.br/data/documents/ storedDocuments/\%7BB8EF5DAF-23AE-4891-AD361903553A3174\%7D/\%7B6B12D137-92DF-4CF5-A35A482AED64CBC0\%7D/BOLETIM2006internet.pdf.> Acesso em: 01 maio 2007. na base permanente de textos do site.

MOUILLAUD, Maurice; PORTO, Sérgio Dayrell (org.). 0 jornal da forma ao sentido. Brasília: Paralelo 15, 1997.

MOURA, Maria Betânia do Socorro. 0s nós da teia: desatando estratégias de faticidade jornalística. São Paulo: Annablume, 2006.

PARKER, Richard; BARBOSA, Regina. (org.).

Sexualidades brasileiras. Rio de Janeiro: RelumeDumará, 1996.

PARKER, Richard. Abaixo do equador. Rio de Janeiro: Record, 2002. 
POLLAK, Michael. Os homossexuais e a Aids sociologia de uma epidemia. São Paulo: Estação Liberdade, 1990.

PONTE, Cristina. Para entender as notícias - linhas

de análise do discurso. Florianópolis: Insular, 2005.

PRADO, Marco Aurélio M. (coord.). Participação, política e homossexualidade: $8^{\mathrm{a}}$ parada GLBT de Belo Horizonte. Belo Horizonte: Prefeitura Municipal, 2006.

SILVEIRINHA, Maria João. 0 lançamento da moeda européia e seus enquadramentos na imprensa. In: CONGRESSO BRASILEIRO DE CIÊNCIAS DA COMUNICAÇÃ̃, $28^{\circ}$, 2005, Rio de Janeiro. Anais... Rio de Janeiro: Intercom, 2005. In: <http:// reposcom.portcom.intercom.org.br/dspace/ bitstream/1904/18029/1/R0199-1.pdf>. Acesso em: em 25 jan. 2007. Está na base permanente de textos do site. SMIGAY, Karin Ellen von. Sexismo, homofobia e outras expressões correlatas de violência: desafios para a psicologia política. Psicologia em Revista, Belo Horizonte, v. 8. n. 11, p. 32-46, jun. 2002.

SODRÉ, Muniz. Reinventando a cultura: a comunicação e seus produtos. Petrópolis: Vozes, 1996.

TRAQUINA, Nelson (org.). Jornalismo: questões, teorias e "estórias". Lisboa: Vega, 1993.

TUCHMAN, Gaye. Making the text. New York: Free Press, 1977.

VERÓN, Eliseo. El cuerpo de las imagens. Bogotá: Norma Editorial, 2001.

WOLF, Mauro. Teorias da comunicação. Lisboa: Editorial Presença, 1994. 


\begin{tabular}{|c|c|}
\hline $\begin{array}{l}\text { About journalism and } \\
\text { homofobia or: do you think } \\
\text { it is easy to talk about it? }\end{array}$ & $\begin{array}{l}\text { Sobre periodismo y } \\
\text { homofobia 0: ¿piensa } \\
\text { que es fácil hablar? }\end{array}$ \\
\hline $\begin{array}{l}\text { Abstract } \\
\text { This article focuses on the relations between } \\
\text { journalism and homophobia, taking as reference } \\
\text { major Brazilian newspapers and TV news programs. } \\
\text { For such, firstly it considers some important aspects } \\
\text { of Western sexual life, particularly what contributes } \\
\text { for homophobic actions and speeches. Secondly, } \\
\text { it critically observes the journalistic process of } \\
\text { construction of realities. Articulating both, are } \\
\text { the journalistic ways of saying, pressed by moral } \\
\text { rules of silence and traditional and contemporary } \\
\text { uses of linguistic forms. It does not consider any } \\
\text { specific case analysis, but attempts to indicate some } \\
\text { theoretical and methodological aspects for other } \\
\text { studies on journalism and homophobia. } \\
\text { Keywords } \\
\text { Journalism. Homophobia. Gender. }\end{array}$ & $\begin{array}{l}\text { Resumen } \\
\text { Este artículo se centra en las relaciones entre } \\
\text { el periodismo y la homofobia, teniendo como } \\
\text { referencia los principales periódicos de Brasil } \\
\text { y los programas de noticias de televisión. Por } \\
\text { ello, en primer lugar, considera algunos aspectos } \\
\text { importantes de la vida sexual occidental, en } \\
\text { particular lo que contribuye para los discursos } \\
\text { y acciones homofóbicos. En segundo lugar, se } \\
\text { observa el proceso periodístico de construcción } \\
\text { de realidades. Entre una y otra, están las maneras } \\
\text { del decir periodístico, presionado por el silencio } \\
\text { de las normas morales y tradicionales y los usos } \\
\text { de formas lingüísticas. No se considera el análisis } \\
\text { de casos concretos, pero se intenta indicar } \\
\text { algunos aspectos teóricos y metodológicos para } \\
\text { otros estudios sobre el periodismo y la homofobia. } \\
\text { Palabras clave } \\
\text { Periodismo. Gênero. Homofobia. }\end{array}$ \\
\hline
\end{tabular}




\section{Expediente}

A revista E-Compós é a publicação científica em formato eletrônico da Associação Nacional dos Programas de Pós-Graduação em Comunicação (Compós). Lançada em 2004, tem como principal finalidade difundir a produção acadêmica de pesquisadores da área de Comunicação, inseridos em instituições do Brasil e do exterior.
E-COMPÓS I www.e-compos.org.br I E-ISSN 1808-2599

Revista da Associação Nacional dos Programas de Pós-Graduação em Comunicação. Brasília, v.12, n.2, maio/ago. 2009

A identificação das edições, a partir de 2008 passa a ser volume anual com três números.

\section{CONSELHO EDITORIAL}

\section{Afonso Albuquerque}

Universidade Federal Fluminense, Brasil

Alberto Carlos Augusto Klein

Universidade Estadual de Londrina, Brasi

Alex Fernando Teixeira Primo

Universidade Federal do Rio Grande do Sul, Brasi

\section{Alfredo Vizeu}

Universidade Federal de Pernambuco, Brasil

Ana Carolina Damboriarena Escosteguy

Pontifícia Universidade Católica do Rio Grande do Sul, Bras

Ana Silvia Lopes Davi Médola

Universidade Estadual Paulista, Brasil

André Luiz Martins Lemos

Universidade Federal da Bahia, Brasil

Ângela Freire Prysthon

Universidade Federal de Pernambuco, Brasil

Antônio Fausto Neto

Universidade do Vale do Rio dos Sinos, Brasil

Antonio Carlos Hohlfeldt

Pontifícia Universidade Católica do Rio Grande do Sul, Brasil

Arlindo Ribeiro Machado

Universidade de São Paulo, Brasil

César Geraldo Guimarães

Universidade Federal de Minas Gerais, Brasil

Cristiane Freitas Gutfreind

Pontifícia Universidade Católica do Rio Grande do Sul, Brasil

Denilson Lopes

Universidade Federal do Rio de Janeiro, Brasil

Eduardo Peñuela Cañizal

Universidade Paulista, Brasi

Erick Felinto de Oliveira

Universidade do Estado do Rio de Janeiro, Brasil

Francisco Menezes Martins

Universidade Tuiuti do Paraná, Brasil

Gelson Santana

Universidade Anhembi/Morumbi, Brasi

Hector Ospina

Universidad de Manizales, Colômbia

leda Tucherman

Universidade Federal do Rio de Janeiro, Brasil

Itania Maria Mota Gomes

Universidade Federal da Bahia, Brasil

Janice Caiafa

Universidade Federal do Rio de Janeiro, Brasil

Jeder Silveira Janotti Junior

Universidade Federal da Bahia, Brasil

\section{João Freire Filho}

Universidade Federal do Rio de Janeiro, Brasil

John DH Downing

University of Texas at Austin, Estados Unidos

José Luiz Aidar Prado

Pontifícia Universidade Católica de São Paulo, Brasil

José Luiz Warren Jardim Gomes Braga

Universidade do Vale do Rio dos Sinos, Brasil

Juremir Machado da Silva

Pontifícia Universidade Católica do Rio Grande do Sul, Brasil

Lorraine Leu

University of Bristol, Grã-Bretanha

Luiz Claudio Martino

Universidade de Brasília, Brasil

Maria Immacolata Vassallo de Lopes

Universidade de São Paulo, Brasil

Maria Lucia Santaella

Pontifícia Universidade Católica de São Paulo, Brasil

Mauro Pereira Porto

Tulane University, Estados Unidos

Muniz Sodre de Araujo Cabral

Universidade Federal do Rio de Janeiro, Brasil

Nilda Aparecida Jacks

Universidade Federal do Rio Grande do Sul, Brasil

Paulo Roberto Gibaldi Vaz

Universidade Federal do Rio de Janeiro, Brasil

Renato Cordeiro Gomes

Pontifícia Universidade Católica do Rio de Janeiro, Brasil

Ronaldo George Hela

Universidade do Estado do Rio de Janeiro, Brasil

Rosana de Lima Soares

Universidade de São Paulo, Brasil

Rossana Reguillo

Instituto Tecnológico y de Estudios Superiores do Occidente, México

Rousiley Celi Moreira Maia

Universidade Federal de Minas Gerais, Brasil

Sebastião Carlos de Morais Squirra

Universidade Metodista de São Paulo, Brasil

Simone Maria Andrade Pereira de Sá

Universidade Federal Fluminense, Brasil

Suzete Venturelli

Universidade de Brasília, Brasil

Valério Cruz Brittos

Universidade do Vale do Rio dos Sinos, Brasil

Veneza Mayora Ronsini

Universidade Federal de Santa Maria, Brasil

Vera Regina Veiga França

Universidade Federal de Minas Gerais, Brasil
COMISSÃO EDITORIAL

Ana Gruszynski I Universidade Federal do Rio Grande do Sul, Brasil Felipe da Costa Trotta I Universidade Federal de Pernambuco, Brasil Rose Melo Rocha I Escola Superior de Propaganda e Marketing, Brasil

\section{CONSULTORES AD HOC}

Aníbal Francisco Alves Bragança I Universidade Federal Fluminense, Brasil Benjamim Picado I Universidade Federal da Bahia, Brasil

Carlos Eduardo Franciscato I Universidade Federal de Sergipe, Brasi

Christa Liselote Berger I Universidade Vale do Rio dos Sinos, Brasil

Gisela Castro I Escola Superior de Propaganda e Marketing, Brasil

Luciana Pellin Mielniczuk I Universidade Federal de Santa Maria, Brasi

Marcia Benetti I Universidade Federal do Rio Grande do Sul, Brasil

Paulo Cunha Carneiro Filho I Universidade Federal de Pernambuco, Brasil

Raquel Recuero I Universidade Católica de Pelotas, Brasil

REVISÃO DE TEXTO E TRADUÇÃO I Everton Cardoso

EDITORAÇÃO ELETRÔNICA I Raquel Castedo
COMPÓS I www.compos.org.br

Associação Nacional dos Programas de Pós-Graduação em Comunicação

Presidente

Itania Maria Mota Gomes

Universidade Federal da Bahia, Brasil

itania@ufba.br

Vice-presidente

Julio Pinto

Pontifícia Universidade Católica de Minas Gerais, Brasil

juliopinto@pucminas.br

Secretária-Geral

Ana Carolina Escosteguy

Pontifícia Universidade Católica do Rio Grande do Sul, Brasil

carolad@pucrs.br 